UDC: $821.134(7 / 8) .09-1$

DOI: https://doi.org/10.18485/beoiber.2021.5.1.4

\author{
Tamara Kedić ${ }^{1}$ \\ Samostalni istraživač \\ Srbija
}

\title{
MIT O LEDI I LABUDU POSMATRAN KROZ PRIZMU RUBENA DARIJA („LEDA") I DELMIRE AGUSTINI („EL CISNE”)
}

\begin{abstract}
Rezime
Književni pokret modernizam nastao je na tlu Hispanske Amerike krajem XIX veka i iznedrio je vrlo značajne hispanoameričke pesnike, a sa sobom je doneo i novine u poeziji. Teme potekle iz klasične istorije i mitologije, istočnjačkih civilizacija i prehispanske Amerike obrađivane su na originalan način, što predstavlja jedan od njegovih glavnih novina. To ujedno čini i temu ovog rada koji se bavi obradom grčkog mita sa tačke gledišta nikaragvanskog pesnika Rubena Darija (Rubén Darío, 1867-1916) i urugvajske pesnikinje Delmire Agustini (Delmira Agustini, 1886-1914). U pitanju je mit o Ledi i labudu, te su korpusom obuhvaćene pesme „Leda” („Leda”) Rubena Darija i „Labud” („El cisne”) Delmire Agustini. Cilj istraživanja je da se komparativnom analizom ukaže na sličnosti i razlike u obradi gorepomenutog mita. Imajući na umu da je Delmira Agustini deo druge generacije hispanoameričkih modernista, tzv. postmodernista, a Ruben Dario najznačajniji predstavnik hispanoameričkog modernizma na njegovom vrhuncu, interesantno je, s jedne strane, porediti njihovu interpretaciju i viđenje ovog helenskog mita, a $\mathrm{s}$ druge strane, ukazati na to u kojoj meri se mitološki i simbolistički elementi usvajaju, prevazilaze i, na kraju, podudaraju u odabranim pesmama. Njihova tumačenja ovog mita se umnogome razlikuju, a do ovakvog zaključka smo došli sistematičnom analizom već pomenutih pesama.
\end{abstract}

Ključne reči: Ruben Dario, Delmira Agustini, grčka mitologija, Leda, labud.

\section{EL MITO DE LEDA Y EL CISNO OBSERVADO A TRAVÉS DEL PRISMA DE RUBÉN DARÍO («LEDA») Y DELMIRA AGUSTINI («EL CISNE»)}

\section{Resumen}

El movimiento literario llamado «el modernismo» se originó en Hispanoamérica, creó una lista de los poetas muy importantes en la literatura hispanoamericana y trajo consigo unas novedades en la poesía. Los temas provenientes de la historia y la mitología clásica, la civilización oriental y la América prehispánica se trataron de forma original, lo que representa una de sus novedades principales. Este es también el tema

1 tamarakedic996@gmail.com 
de este trabajo dedicado a la elaboración del mito de la mitología griega desde el punto de vista de Rubén Darío (1867-1916) y Delmira Agustini (Delmira Agustini, 1886-1914). Se trata del mito sobre Leda y el cisne y el corpus incluye los poemas «Leda» del poeta nicaragüense y «El cisne» de la poetisa uruguaya. Nuestro objetivo es señalar las similitudes y diferencias en la elaboración del mito ya mencionado mediante el análisis comparativo. Teniendo en cuenta que Delmira Agustini forma parte de la segunda generación de modernistas, de los llamados «posmodernistas», y que Rubén Darío es el representante más importante del modernismo en su apogeo, es interesante, por un lado, comparar sus interpretaciones y visiones de este mito helénico, y por otro lado, señalar en qué medida se adoptan, superan y, en última instancia, coinciden los elementos mitológicos y simbolistas en los poemas seleccionados.

Palabras clave: Rubén Darío, Delmira Agustini, mitología griega, Leda, cisne.

\section{THE MYTH OF LEDA AND THE SWAN OBSERVED THROUGH THE PRISM OF RUBÉN DARÍO ("LEDA") AND DELMIRA AGUSTINI ("EL CISNE")}

\section{Summary}

The literary movement modernismo originated in Spanish America and gave birth to very important poets in Spanish American literature, bringing about novelties in poetry. Topics originating from classical history and mythology, Eastern civilizations and pre-Hispanic America were treated in an original way, which is one of its main novelties. That is also the topic of this paper, which considers the treatment of the Greek myth from the point of view of Nicaraguan poet Rubén Darío (1867-1916) and Uruguayan poet Delmira Agustini (Delmira Agustini, 1886-1914). The myth in question is about Leda and the swan, and the corpus includes the poems "Leda" ("Leda") written by Darío and "The Swan" ("El cisne") written by Agustini. The aim of this article is to point out the similarities and differences in the treatment of the aforementioned myth. Bearing in mind that Delmira Agustini is a part of the second generation of modernists, the so-called postmodernists, and Ruben Dario is the most important representative of modernismo at its peak, it is interesting, on one hand, to compare their interpretations and visions of this Hellenic myth, and on the other hand, to point out the extent to which mythological and symbolist elements are adopted, surpassed and, ultimately, matched in selected poems. Their interpretations of this myth differ greatly, and we came to this conclusion through a systematic analysis of the mentioned poems.

Key words: Rubén Darío, Delmira Agustini, Greek mythology, Leda, swan.

Kada je reč o hispanskom modernizmu, još uvek se vodi polemika o njegovom poreklu. Jedna grupa teoretičara smatra da modernizam vodi poreklo od španske pesničke Generacije '98 dok se druga grupa zalaže za tvrdnju da je on nastao na hispanoameričkom tlu zahvaljujući Rubenu Dariju (Rubén Darío) koji je prvi put upotrebio kovanicu „modernizam” (modernismo) 1888. godine kako bi označio novu grupu pesnika okarakterisanih kao "moderni”. Ovaj književni pravac počiva na romantičarskoj tradiciji i to, pre svega, francuskoj. Modernistički pesnici su verovali da reči imaju moć da promene svet, zbog čega su težili da putem poezije stvore inovativnu koncepciju života zasnovanu na kosmopolitizmu i panteizmu. Težilo se učenom jeziku, a senzualnost i ritmičnost su dobile na značaju. Žena je idealizovana, sinonim za estetski 
užitak, te se često peva o Veneri, Ledi i Jeleni Trojanskoj. Elegancija je jedna od primarnih karakteristika modernizma, te se labud asocijativno povezuje s ovim pravcem jer i on, kao i modernizam, postoji i živi da bi bio elegantan i lep (Hernández 2015: 73-75).

Sve ovo nas navodi da tumačimo obradu helenskog mita o Ledi i labudu $u$ hispanoameričkoj poeziji (post)modernizma, a kako bismo je predstavili što podrobnije, analiza će počivati na tumačenju pesme najznačajnijeg predstavnika modernizma, Rubena Darija, i pesnikinje Delmire Agustini (Delmira Agustini), čija je pripadnost modernističkom pravcu još uvek pod znakom pitanja jer njeno stvaralaštvo pokazuje i odlike postmodernizma. Ovo dvoje pesnika od legende o Ledi i labudu stvaraju sopstvenu i međusobno značajno različitu interpretaciju, i to je ono što se nastoji dokazati na stranama koje slede.

Nikaragvanski pesnik Ruben Dario i urugvajska pesnikinja Delmira Agustini su vrlo često, kada se govori o umetničkom ostvarenju, posmatrani kao dvoje pesnika koji uspostavljaju dijalog putem alegoričnih pesama i to prvenstveno kada je reč o unutrašnjoj teskobi u samom činu stvaranja (Pleitez Vela 2016: 93).

Dario je, budući dvadeset godina stariji, izvršio veliki uticaj na Agustini, te ga je ona smatrala svojim „pesničkim ocem”. O njihovoj ličnoj i profesionalnoj bliskosti govori i sledeći citat koji se bazira na Dariovim rečima upućenih pesnikinji: „De todas cuantas mujeres hoy escriben en verso ninguna ha impresionado mi ánimo como Delmira Agustini" (Darío 2000: 223). ${ }^{2}$

Prve pesme Delmire Agustini, objavljene početkom XX veka jasno pokazuju uticaj modernizma i stila nalik onom koji je Ruben Dario negovao u svojim pesmama. Neosporno je da pesnik iz Nikaragve izvršio veliki uticaj na Agustini, ali se ipak u njenom stvaralaštvu primećuje postepeno odvajanje od tipične modernističke tradicije i od Darija kao njenog najvećeg predstavnika. Agustini počinje da stvara na temeljima modernističke tradicije, ali je postepeno deformiše i transformiše kako bi je prilagodila svojoj pesničkoj viziji. Novija istraživanja pokazuju da Delmira Agustini svojom poezijom prevazilazi ideološke i estetske postulate modernizma, kao i njegova retorička sredstva, a za takvo mišljenje je nesumnjivo zaslužna subverzivna upotreba nekih modernističkih simbola i napuštanje utvrđenih pesničkih formi koje su izazvale zaprepašćenje ne samo književnih kritičara, već i buržoazije toga doba (Castillo 1998: 70). Francuski pisac Erve L'Kor (Hervé Le Corre 2001: 242) kaže da je jezik Delmire Agustini, iako modernistički, u suštini erotičan, a njena poezija ljubavna.

Tanja Pleites Vela (Tania Pleitez Vela 2016: 84) u svom članku „Delmira Agustini, prelazeći i prevazilazeći Dariovu orbitu” („Delmira Agustini, transitando y superando la

2 "Od svih žena koje danas pišu u stihu, nijedna nije inspirisala moju dušu kao Delmira Agustini."

Prevod autora rada, osim ako nije drugačije navedeno. 
órbita dariana") naglašava da Agustini nije prva pesnikinja koja je uvela erotske teme $u$ svoje stvaralaštvo, ali je svakako jedna od žena koje su zbog svoje ekscentrične poezije ostavile najviše traga $u$ istoriji književnosti. Njene preteče $u$ obradi erotskih tema su kubanske pesnikinje Hertrudis Gomes de Aveljaneda (Gertrudis Gómez de Avellaneda, 1814-1873) i Mersedes Matamoros (Mercedes Matamoros, 1851-1906). Ipak, Alberto Sum Felde (Alberto Zum Felde apud Pedraza Jiménez 2005: 340), urugvajski istoričar, kritičar i esejista, ističe da je „este sentido trascendental de su libido es lo que diferencia genéricamente su poesía de la poesía erótica en general, y en especial del erotismo de otras poetisas modernas". ${ }^{3}$

Kako ističe Tanja Pleites Vela (2016: 84):

El centro de la escritura agustiniana radica, precisamente, en la búsqueda de un lenguaje y un simbolismo que expresen el erotismo a partir de una experiencia que se origina en el cuerpo de una mujer. Esto contrasta con la poesía de Rubén Darío que, con su exhibición simbólica de la sexualidad y sus interpretaciones eróticas del mundo, brindó una de las representaciones más convencionales del erotismo, esto es, desde el punto de vista masculino heterosexual. ${ }^{4}$

Mersedes Serna (Mercedes Serna apud Pleitez Vela 2016: 84) se pita: „¿Podía una mujer intelectual y poeta continuar con una tradición literaria en que la mujer es objeto sexual, sufre el sadismo del hombre y es víctima de sus fantasías?"5 Kao odgovor na to pitanje javlja se feministička poetika i retorika Delmire Agustini koja, s jedne strane, nastoji da neutrališe ideološki dualizam karakterističan za modernizam, a proizašao je iz patrijarhalne filozofske (platonske) i religijske (judeohrišćanske) tradicije i da, s druge strane, sruši marginalnu i pasivnu ulogu koju modernistička poetika pripisuje ženi kada je predstavi kao objekat muške požude. Agustini nastoji da figuru žene pripoji falocentričnom svetu kakav je bio modernistički (Castillo 1998: 71-73).

Neizbežno je spomenuti uticaj francuskog parnasizma i simbolizma na hispanoamerički modernizam kom su $u$ amanet ostavili simbol labuda. Setimo se Malarmeovog soneta "Labud” objavljenog 1885. godine u kojoj je labud simbol pesnika koji se nalazi pred stvaralačkom nemoći jer je zarobljen u zaleđenom jezeru. Pesnik teži

\footnotetext{
3 ,transcendentalni smisao njenog libida ono što generički razlikuje njenu poeziju od erotske poezije uopšte, a pogotovo od erotizma drugih savremenih pesnikinja."

4 "Suština pisanja Delmire Agustini počiva upravo na potrazi za jezikom i simbolizmom koji bi iskazali erotizam iz iskustva koje proističe iz tela žene. To se suprotstavlja poeziji Rubena Darija koji je svojim simboličkim prikazom seksualnosti i svojim erotskim prikazima sveta pružio jednu od najkonvencionalnijih predstava erotizma s tačke gledišta jednog heteroseksualca."

5 "Da li je jedna žena intelektualac i pesnik mogla da nastavi književnu tradiciju u kojoj je žena seksualni objekat, trpi sadizam od strane muškarca i žrtva je njegovih fantazija?"
} 
ka savršenstvu i lepoti, ali ga okruženje u kom živi u tome sprečava (Martínez Cuadrado 2001-2002: 91-92). Tako je i Dario, kako bi bez zadrške govorio o svojim osećanjima oslobađajući se bilo kakvih optužbi tadašnjeg vremena i društva na svoj račun zbog erotskih motiva, inspiraciju morao da crpi iz nekog drugog, dalekog univerzuma, što je $u$ ovom slučaju helenski svet sa svojom bogatom mitologijom.

Simbolom labuda bavio se i Pedro Salinas koji, u svom eseju „Labud i sova: beleške o istoriji modernističke poezije , (1940) („El cisne y el búho: apuntes para la historia de la poesía modernista"), navodi da labud ima dvostruko značenje u modernističkoj tradiciji; s jedne strane, labud predstavlja senzualnu i telesnu strast koja se temelji na helenskom mitu, a sa druge strane, Salinas ističe romantičarsku i sentimentalnu koncepciju labuda koju je popularizovao Rihard Vagner u svojoj operi Loengrin (Lohengrin) sredinom XIX veka (Pleitez Vela 2016: 94).

Figura labuda je kod Darija doživljavala transformaciju iz pesme u pesmu. U pesmi „Grb” („Blasón”) ona je kultura, u „Labudu” („El cisne”) nova poezija, u pesmi „Ja jurim jedan oblik" („Yo persigo una forma”) enigma umetničkog stvaranja, a u pesmama o Ledi, kojima pripada i ova, labud simbolizuje erotizam (Pleitez Vela 2016: 94). Kao što je labud u Dariovom pesništvu doživljavao postepenu evoluciju, tako su se menjali i pesnik, i njegova vizija prilagođavajući se promenama u svetu i vremenu u kom je živeo. Iz ovoga se može zaključiti da labud predstavlja suštinu Dariove estetike, njegov ukus za prefinjeno, odabrano, klasično; on je nosilac Dariove kosmovizije i ideala modernističke poetike (Hernández 2015: 85). Silvija Moloj (Sylvia Molloy 1983: 16) objašnjava da je Agustini tokom pisanja svojih pesama „Labud” i „Nokturno” („Nocturno”) nužno imala na umu pesme svog preteče Rubena Darija; ali, njen labud je revolucionaran u odnosu na Dariovog, isto kao i slavni sonet Gonsalesa Martinesa (González Martínez) „Uvrni vrat labudu..." („Tuércele el cuello al cisne...”) napisan tri godine ranije. Moloj (Molloy 1983: 16) dalje ističe da se najveći poduhvat urugvajske pesnikinje ogleda $u$ tome što raskida sa Dariovom poetikom transformišući čuveni simbol labuda, dakle, ne odbacujući ga, već inkorporirajući ga u svoju pesmu (za razliku od Gonsalesa Martinesa koji ga u potpunosti zamenjuje drugim simbolom - sovom).

Kada uporedimo sliku Lede (i žene uopšte) u njihovim pesmama, reč je o posve razlličitim prikazima. To najbolje ilustruju reči Tanje Pleites Vele (2016: 89) koja kaže da:

Darío perfila a la mujer como objeto de deseo y lo hace representándola en dos vertientes: ya sea a través de la imagen de la amada pura, virginal e intangible típicamente romántica, o de la mujer-pasión, es decir, la femme fatale, propia del decadentismo finisecular. En otras ocasiones, a la mujer se le adjudica, como máximo, el papel de intermediaria entre el Poeta-Hombre y el Arte, es decir, se le convierte en la musa inspiradora. Pero Agustini cambia los papeles. Es cierto que, en parte, la uruguaya reproduce figuras o modelos 
femeninos patriarcales; pero la diferencia es que ella los presenta matizados y profundamente erotizados. ${ }^{6}$

Upravo je mit o Ledi i labudu poslužio kao umetnička spona između Delmire Agustini i Rubena Darija koji na primeru pesama sa istim mitološkim okvirom jasno pokazuje različitosti u slobodi i načinu izražavanja i tumačenju pomenutih simbola.

Postoji više verzija ovog mita od kojih jedna kaže da je Leda, žena spartanskog kralja Tindareja, svojom lepotom očarala i samog boga Zevsa. Zevs se preobratio u labuda i bacio joj se u naručje. Potom ju je na silu obljubio. Druga verzija kaže da je Zevs, bežeći od orla koji ga je proganjao, zaštitu potražio u Ledinom naručju. Metamorfozom se preobratio u predivnog labuda i zaveo ju je (Hernández 2015: 76).

Dariova pesma "Leda“ je objavljena u madridskom časopisu La España moderna u novembru 1899. godine, iako je napisana sedam godina ranije u San Hoseu, glavnom gradu Kostarike (Martínez Cuadrado 2001-2002: 96). U okviru svog falocentričnog univerzuma, Dario bira, ni manje ni više do vrhovnog grčkog boga, boga nad svim bogovima, kako bi kroz njega izrazio muškost i erotizam. On poseduje apsolutnu moć koja mu omogućava da zadovolji svoja čula i čežnje, ali istovremeno poseduje i najveću slabost prouzrokovanu emocijama, što ga spušta na ravan običnog i zemaljskog. Ako posmatrano ovu pesmu iz drugog ugla, možemo govoriti i o apoteozi Lede, budući da je Zevsova čežnja uzdiže na božanske visine.

Zevs je u Dariovoj pesmi sreo Ledu dok se šetala pored reke Eurote „en las linfas sonoras"7 (Darío 2001: 121). Interesantno je što Dario za deskripciju vode upotrebljava reč "onda", a ne „ola". 8 "Ola" se odnosi na talase koji su prouzrokovani vetrom, a „onda" se odnosi na kretanje vode koje je prouzrokovano na neki drugi način. Naslućuje se da je labud $\mathrm{u}$ vodi i da on izaziva talasanje. Upotreba prideva azulado, odnosno plavkasto, sugeriše da je u pitanju podne, jer je plavetnilo vode najizraženije oko podneva, kad je sunce tik iznad jezera. U trećoj strofi saznajemo ko je labud zapravo „olímpico pájaro herido de amor"9 (Darío 2001: 121), aludirajući na Zevsa. Deo stiha "labios en flor"10 (Darío 2001: 121) može se interpretirati dvojako. Sa jedne strane, može se tumačiti kao aluzija na mladost, a sa druge strane, konotativno može upućivati na slike erotskog

\footnotetext{
6 „„Dario oslikava ženu kao predmet požude i to čini predstavljajući je na dva načina: bilo kroz sliku čiste drage, nevine i nedodirljive, tipično romantičarske, bilo kroz sliku strasne, odnosno fatalne žene, tipične za dekadenciju s kraja XIX veka. U drugim prilikama se ženama dodeljuje, uglavnom, uloga posrednika između Pesnika-Muškarca i Umetnosti, odnosno ona postaje muza koja ga inspiriše. Ali Agustini menja uloge. Tačno je da Urugvajka, jednim delom, reprodukuje ženske patrijarhalne figure ili modele, ali razlika je u tome što ih ona predstavlja iznijansiranim i duboko erotizovanim."

7 „u zvučnim limfama”

8 U srpskom jeziku se ne pravi razlika između pojma „onda” i „ola”. Na srpski se prevodi kao „talas”.

9 "olimpijska ptica ranjena ljubavlju"

10 "usne u cvatu”
} 
karaktera, posebno ako mu pridružimo sliku kljuna kao falusnog simbola. Pored mnogih modernističkih elemenata u ovoj pesmi, kao što su "ámbar", „el lago azulado”, "seda”, "flor", odnosno „ćilibar”, ,plavkasto jezero”, ,"svila”, „cvet/cvat”, boje su takođe važan modernistički element. Kod Darija se boja u svakoj strofi odnosi na određeni deo dana: od zore, odnosno svitanja, pa sve do sumraka, labud menja boje od bele, preko ružičaste, do srebrne. Kljun od ćilibara ukazuje na njegovu prozirnost na suncu. Nije slučajna povezanost ćilibara sa suncem jer je on simbol sunčeve i božanske privlačne snage, a ponovno rađanje sunca sugeriše večni život, naglašavajući na taj način labudovu, odnosno Zevsovu besmrtnost. Potom, srebro je metal koji se povezuje sa mesecom, a preko njega i sa ženskim telom, i to putem veze između lunarnog i fiziološkog ciklusa žene. Labudova bela boja, koja podseća na sneg, simbolizuje čistotu i povezuje se sa Venerom, boginjom ljubavi koja je belog labuda smatrala svetom životinjom (Lodato 1999: 116-117).

Poslednja dva stiha sadrže aliteraciju, ponavljanje suglasnika ,"s", čime se oponaša šuštanje lišća: „del fondo verdoso de fronda tupida / chispean turbados los ojos de Pan”11 (Darío 2001: 121). Ovom stilskom figurom se na originalan način u poslednjoj strofi uvodi novo lice iz grčke mitologije - bog Pan. Pan je u klasičnoj mitologiji prikazan kao zaštitnik pastira i stada u Arkadiji. Takođe se pripoveda i o Panovoj sklonosti ka skrivanju u šumi i žbunju kako bi krišom posmatrao nimfe, te je njegovo prisustvo u pesmi sasvim jasno. U književnosti se Pan uglavnom povezuje sa seksualnom željom i nagonom (Cuello Privitera 2017: 137). On iz prikrajka posmatra Ledu i Zevsa. U tom smislu, Pan kao nemi posmatrač stoji izvan radnje i čitaoci se mogu poistovetiti s njim.

Dario ovom pesmom u svoju poeziju uvodi nešto novo, do tog momenta nikad viđeno $u$ njegovom stvaralaštvu, a to je silovanje kao sredstvo kom labud pribegava $u$ ophođenju prema Ledi kako bi dostigao zadovoljstvo (Hernández 2015: 85). Ako sagledamo Dariovu pesmu u širem kontekstu, ova novina se mogla protumačiti, kako Ernandes (2015: 85) zaključuje u svom radu „Evolucija labuda u poeziji Rubena Darija” („La evolución del cisne en la poesía de Rubén Darío”), kao pesnikova poruka da istinsko umetničko stvaralaštvo, poput ljubavi i strasti, počiva na neprestanom sukobu između razuma i osećajnosti, pri čemu je ravnoteža između njih nestabilna i promenljiva jer uvek na kraju jedna sila nadvlada drugu i nametne joj se. Kada bismo nastavili sa tumačenjem mita o Ledi i labudu u Dariovom stvaralaštvu na metaforičkom planu, došli bismo do još nekih mogućih interpretacija. Ako labuda poistovetimo sa pesnikom, a Ledu sa muzom koja je večiti izvor inspiracije, iz njihovog sjedinjavanja se rađa Jelena Trojanska, simbol lepote. Suština se nalazi u alegorijskom prikazu pesnika pred naletom inspiracije koju ne može da kontroliše i iz koje se rađa pesma kao simbol savršenstva (Cuello Privitera 2017: 141).

11 „u zelenkastoj pozadini gustoga žbunja / blistaju zbunjene oči Pana” 
Dariove pesme u kojima je labud nosilac najrazličitijih značenja su od neprocenjivog značaja za poeziju napisanu na španskom jeziku jer, kako Maraso (Marasso apud Cuello Privitera 2017: 149) kaže, „en grandes alas sacras se eleva el verso castellano"12.

Pesma "Labud” urugvajske pesnikinje nalazi se u zbirci Prazni kaleži (Los cálices vacíos, 1913) i predstavlja jednu od pesama Delmire Agustini koje su se najčešće koristile kako bi se uspostavio tekstualni dijalog sa Darijem (Pleitez Vela 2016: 98). Pesme posvećene erotskim predstavama libida u pesnikinjinom opusu su kulminaciju doživele u gorepomenutoj zbirci (Lanieri 2002: 423), gde Agustini preuzima panerotizam karakterističan za Dariovu poeziju, ali ga transformiše i prilagođava svojoj pesničkoj estetici, budući da erotizam prisutan u njenim stihovima odstupa od falocentrizma prisutnog u modernizmu (Castillo 1998: 72). Agustini u pesmi „Labud” daje originalno viđenje već poznatog modernističkog amblema13 (Oviedo 2001: 36).

Ova pesma se može tumačiti na više načina. Šire posmatrano, "Labud“ je metapesma - pesma o pesmi. U tom smislu, ako govorimo o pesmi urugvajske pesnikinje kao o alegoriji, jezero, koje se pominje na početku, moglo bi, u širem smislu, da predstavlja poeziju, pisanu reč, samoizražavanje, odnosno, stranu ili papir, u užem smislu. U jezeru živi labud - pesnički duh, duša i intelekt, odnosno, pesma.

U kristalno čistom jezeru (pesmi) ogledaju se pesnikinjina osećanja. Na taj način pesma dobija autoreferencijalni karakter. Stih „un cisne con dos pupilas humanas” 14 (Agustini 2000: 255) takođe je metafora. Zenice aludiraju na ogledalo, odraz. Tako posmatrano, u labudovim očima se ogleda stvaranje pesme, a rađanjem pesme, rađa se i ona, lirski subjekt, kao pesnikinja (Beaupied 1996: 135-136).

Kako pesma odmiče, sve je primetniji erotski naboj. Čisto i božansko ustupa mesto erotskom susretu i labud se pretvara u ljubavnika. Za razliku od Dariove pesme, u ovoj pesmi je lirski subjekt onaj koji se nudi labudu s ciljem da ostvari fizički kontakt.

Labud je u pesmi Delmire Agustini nosilac atributa ljudskog bića. Humanizacija labuda je u kontrastu sa parnasovskim modelom labuda kao ideala lepote, poezije i božanstva. Erotizacija labuda se vidi u upotrebi falusnog simbola, npr. "pico en fuego"15 (Agustini 2000: 255). Kljun takođe može da simbolizuje pero, a sangre, odnosno krv mastilo. Lirsko ja nije nemi posmatrač, već aktivno učestvuje u pesmi što dovodi do

\footnotetext{
12 „na velikim sakralnim krilima uzdiže se kastiljanski stih".

${ }^{13}$ Dario i Agustini kreću od istog mita, ali ga predstavljaju na znatno različite načine. Pritom, Agustini ni u jednom trenutku ne ističe direktno da je inspiraciju crpela iz mita, ali se pažljivim iščitavanjem i tumačenjem stihova može podvući određena paralela među njima. Susret Lede i labuda kod Darija je prikazan kao predstava - i čitaoci, i pesnik su izvan radnje i posmatraju scenu. U pesmi Delmire Agustini ne samo što se ne spominje Ledino ime, već se scena odvija u drugačijem pejzažu koji opisuje lirski subjekt. Taj novi ambijent je duboko povezan sa misaonim i nesvesnim (Molloy 1983: 17).

14 ,jedan labud sa dve ljudske zenice"

15 „kljun u vatri”
} 
pucanja još jedne karike u modernističkoj tradiciji jer žene više nemaju isključivo pasivnu ulogu. „Labud” preokreće pozicije unutar binarnog odnosa u kom muškarac ima prevlast nad ženom, te ženama dodeljuje aktivnu ulogu. Lirski subjekt ne potiskuje seksualnu želju, ali i ne deluje obezvređeno, već čvrstim glasom izražava svoje najintimnije želje. Očigledno je da pesnikinjin cilj nije bio da naglasi osobine koje se smatraju ženskim vrlinama, poput skromnosti i čistote, već da istakne tenziju između ličnosti žene i njenih želja. Time se direktno suprotstavlja patrijarhalnoj paradigmi poezije toga doba. Žena je kod Darija uglavnom predstavljana kao predmet posmatranja i divljenja, ona uzbuđuje i budi čežnju, ali se uzbuđenje nikad ne materijalizuje, dok je kod Delmire Agustini ženi dodeljena aktivna uloga, a njen odnos sa muškarcem konkretizovan (Pleitez Vela 2016: 89-90).

Stihovi „,sus alas blancas me turban / como dos cálidos brazos"16 (Agustini 2000: 255) jasno aludiraju na erotski čin. Nakon tog zagrljaja, u pesnikinjinom labudu se, za razliku od Dariovog, javlja vrelina manifestovana kroz prikaz vatre i crvene boje: "ardieron", ,"rubí", „fuego", „rojo", ,pico quemante”, , pico de fuego", odnosno, ,gorele su”, "rubin”, „vatra, crveno", „kljun u plamenu”, „vatreni kljun”, itd. Tu su suprotstavljeni prikazi labuda kod ovo dvoje autora - sve jača groznica pesnikinjinog labuda, i sve veća ispraznost, gubitak boje i hladnokrvnost Dariovog labuda u trenutku silovanja.

Stihovi „Pero en su carne me habla / y yo en mi carne le entiendo"17 (Agustini 2000: 256) udaljavaju Agustini od Darija, jer je prikazan drugačiji vid komunikacije, odnosno, zapaža se dobrovoljna interakcija između žene i labuda, na obostrano zadovoljstvo (Molloy 1983: 16-18).

Na kraju pesme Delmire Agustini, lirski subjekt i labud su obeleženi različitim bojama. Labud je crven zbog svog poetskog i erotskog susreta sa lirskim subjektom koji ostaje bled i iscrpljen posle strastvenog čina. Stihovi „Y yo parezco ofrecerle / todo el vaso de mi cuerpo..."18 (Agustini 2000: 256) narušavaju uobičajenu erotsku sliku. Crvena boja aludira na gubitak nevinosti i na porođaj. U ovom kontekstu, iz poslednje strofe možemo zaključiti da se u sjedinjavanju labuda i pesničkog ,ja" povezuju lirski glas i sopstvene misli, iz čega se rađa pesnikinja. Dakle, kada krv (mrlje od mastila) ispune labuda (ispiše pesmu), tada labud "hunde el pico en mi regazo / y se queda como muerto..."19 (Agustini 2000: 257), odnosno, ostaje miran, smiren, te aludira na statična slova ispisana na hartiji. Rađanje pesme predstavlja rađanje i afirmaciju same pesnikinje. Dublje posmatrano, susret lirskog subjekta i labuda u pesmi urugvajske autorke ujedno predstavlja i susret

\footnotetext{
16 "njegova bela krila me uznemiravaju / poput dve tople ruke"

17 "Ali u svom telu mi govori / a ja ga u svom telu razumem"

18 "I čini mi se da mu nudim / svu tečnost svoga tela..."

19 "zaranja kljun u moje krilo / i izgleda kao da je mrtav..."
} 
Delmire Agustini i Rubena Darija. Taj labud (Dario) izgleda kao da je mrtav, odnosno, pobeđen, osvojen od strane Delmire Agustini (Beaupied 1996: 137-139). Makar morala da piše "al margen del lago claro" 20 (Agustini 2000: 256), odnosno, izvan modernističkog kanona, pesnikinja je samoj sebi dovoljna.

\section{Zaključak}

Komparativna analiza pesama koje su obuhvaćene korpusom ovog rada dala je značajne rezultate. Utvrđene su sličnosti u samom pristupu helenskom mitu o Ledi i labudi, a posebno su istaknute razlike $u$ njihovoj pesničkoj obradi. Dario je u svom stvaralaštvu pružio konvencionalnu sliku ljubavi i seksualnosti protiv koje se pobunila Delmira Agustini pružajući otpor putem pisane reči i stvarajući na taj način neskvadišnju poeziju. Pod "nesvakidašnjim” se podrazumeva pesnikinjina hrabrost da obradi ljubavne teme erotskog karaktera, ali je upravo to dovelo do nastanka nove dimenzije i viđenja ljubavi s tačke gledišta žene s početka XX veka. Baveći se temama koje se tradicionalno smatraju „muškim”, Delmira Agustini narušava tradicionalni modernistički obrazac, igra se simbolima, stvara sopstvene simbole ili već postojećim daje sasvim nova značenja, što je protumačeno kao drskost.

Dario je stvorio sopstveni pesnički mikrokosmos u kom je labud poistovećen sa pesnikom i poezijom uopšte. Nikaragvanski pesnik je svojim delima obuhvatio široku lepezu značenja koja se asocijativno povezuju sa simbolom labuda na koji se oslanjaju mnoge pesničke tradicije. Poetika urugvajske pesnikinje je zasnovana na tim tradicijama, ali se postepeno odvajala od njih.

S jedne strane, peruanski pisac i književni kritičar Hose Migel Ovijedo (José Miguel Oviedo 2001: 36) zamera Delmiri Agustini to što se pridržavala modernističkog književnog kanona i paradigme, zbog čega je njena književnost u trenutku stvaranja patila od nedostatka originalnosti i već „istrošenih” modela, i kaže da je "su gran pecado literario fue resignarse a ser tradicional cuando pudo ser original". ${ }^{21} \mathrm{~S}$ druge strane, španski istoričar književnosti Pedrasa Himenes (Pedraza Jiménez 2005: 339) navodi da je Delmira Agustini jedinstvena pesnikinja svoga doba i da njena originalnost leži upravo u hrabrosti što se usudila da piše na drugačiji način. Ipak, i Pedrasa Himenes je svestan činjenice da "originalno", prema uobičajenom mišljenju, mora podrazumevati raskid sa prethodnom tradicijom i modelima.

\footnotetext{
20 „na ivici bistrog jezera"

${ }^{21}$ „njen veliki književni greh bio to što se podvrgnula tome da bude tradicionalna kada je mogla da bude originalna"
} 
Čitajući stihove Delmire Agustini i Rubena Darija, i nakon više od jednog veka od njihove smrti možemo pratiti kako ovo dvoje izuzetnih pesnika komuniciraju putem modernističkog pesničkog jezika poigravajući se rečima, čulima, simbolima, bojama, motivima i temama. Ove dve pesme su kao lice i naličje jedne iste kovanice iz koje zrači sjaj simbolizma, modernizma i postmodernizma, i sve to u okrilju helenske mitologije.

\section{BIBLIOGRAFIJA}

Agustini, Delmira. «El cisne.» Poesías completas. Magdalena García Pinto (ed.). Madrid: Cátedra, 2000. 255-257. Impreso.

Beaupied, Aída. «Otra lectura de 'El cisne’ de Delmira Agustini.» Letras Femeninas 22.1/2 (1996): 131-142. JSTOR. Web. 13.12.2019.

Castillo, Jorge Luis. «Delmira Agustini o el modernismo subversivo.» Chasqui: revista de literatura latinoamericana 27.2 (1998): 70-84. JSTOR. Web. 15.12.2019.

Cuello Privitera, Tatiana. «El símbolo del cisne en Rubén Darío.» Revista de Literaturas Modernas 47.1 (2017): 135-150. Web. 20.4.2021.

Darío, Rubén. «Leda.» Cantos de vida y esperanza, los cisnes y otros poemas. Francisco J. Díez de Revenga (ed.). Salamanca: Ediciones Almar, 2001. 120-121. Impreso.

—. «Pórtico». Poesías completas. Magdalena García Pinto (ed.). Madrid: Cátedra, 2000. 223. Impreso.

Hernández, Alexander. «La evolución del cisne en la poesía de Rubén Darío.» Realidad 145-146 (2015): 73-88. Web. 30.11.2019.

Lanieri, Morena Carla. «El imaginario erótico femenino en Delmira Agustini y Alfonsina Storni.» La penna di venere: escritture dell'ammore nelle culture iberiche. Atti del XX Convegno [Associazione Ispanisti Italiani]. Vol. 1. Domenico Antonio Cusato e Loretta Frattale (coord.). Firenze: Andrea Lippolis Editore, 2002. 421-434. Web. 27.11.2019.

Le Corre, Hervé. Poesía hispanoamericana posmodernista. Madrid: Editorial Gredos, 2001. Impreso.

Lodato, Rosemary C. Beyond the Glitter: The Language of Gems in Modernista Writers Ruben Dario, Ramon Del Valle-Inclan, and Jose Asuncion Silva. Lewisburg: Bucknell University Press, 1999. 109-118. Web. 5.12.2019.

Mártinez Cuadrado, Jerónimo. «El cisne, leit-motiv de la poesía parnasiana, simbolista y modernista.» Anales de Filología Francesa 10 (2001-2002): 83-99. Web. 25.4.2021.

Molloy, Sylvia. «Dos lecturas del cisne: Rubén Darío y Delmira Agustini.» Revista de la Universidad de México 29 (1983): 14-18. Web. 12.12.2019.

Oviedo, José Miguel. Historia de la literatura hispanoamericana. Postmodernismo, vanguardismo, regionalismo. Tomo III. Madrid: Alianza Editorial, 2001. Impreso. 
Pedraza Jiménez, Felipe B. Manual de la literatura hispanoamericana. Modernismo. Tomo III. Pamplona: Cénlit Ediciones, 2005. Impreso.

Pleitez Vela, Tania. «Delmira Agustini, transitando y superando la órbita dariana.» Mitologías hoy 13 (2016): 83-100. Web. 15.11.2019. 